\title{
PERCEPÇÃO DE ATORES DA POLÍTICA DE SEGURANÇA ALIMENTAR E NUTRICIONAL SOBRE PARTICIPAÇÃO SOCIAL
}

\section{Perception of social participation by actors of the Food and Nutrition Security Policy
Percepción de actores de la Política de Seguridad Alimentaria y Nutricional sobre participación social

\author{
Alessandra Karla Oliveira Amorim Muniz \\ Universidade Estadual do Ceará - UECE- Fortaleza (CE) - Brasil \\ Helena Selma Azevedo \\ Universidade Federal do Ceará - UFC - Fortaleza (CE) - Brasil
}

Letícia de Albuquerque Araújo

Universidade Estadual do Ceará - UECE- Fortaleza (CE) - Brasil

\section{Anna Erika Ferreira Lima}

Instituto Federal de Educação, Ciência e Tecnologia do Ceará - IFCE - Fortaleza (CE) - Brasil

\author{
Maria Marlene Marques Ávila \\ Universidade Estadual do Ceará - UECE - Fortaleza (CE) - Brasil
}

\section{RESUMO}

Objetivo: Analisar a participação social a partir da percepção dos atores sociais que discutem e indicam caminhos para a Política de Segurança Alimentar e Nutricional (SAN). Métodos: Pesquisa realizada pelo método estudo de caso, realizado no período de janeiro a novembro de 2015, em nove municípios maranhenses, mediante aplicação de entrevistas semiestruturadas com 38 conselheiros e membros das câmaras intersetoriais de segurança alimentar e nutricional, sendo 22 da sociedade civil e 16 do poder público. A categoria analítica "participação social" norteou a análise dos dados. Resultados: A participação social foi percebida como "mecanismo de diálogo e conflito", "exercício de controle social", "instrumento para alcance do direito e realização dos anseios da sociedade" e "estratégia para garantir o retorno das proposições da política à comunidade". Conclusão: As percepções dos atores se direcionam para a participação social como um meio de garantir a construção da política de SAN e o alcance do direito à alimentação pela população, porém também sinalizam limitações para o seu efetivo exercício, fato que terá impacto em outras políticas, como a da saúde.

Descritores: Segurança Alimentar e Nutricional; Participação Social; Política Pública.

\section{ABSTRACT}

Objective: To analyze the social participation from the perception held by the social actors who discuss and suggest paths towards Brazil's Food and Nutrition Security Policy. Methods: Research carried out using the case study methodology, in the period from January to November 2015, in nine municipalities of the state of Maranhão, by means of interviews applied to 38 counselors and members of the intersectoral chambers for food and nutrition security, of which 22 represented the civil society and 16 the public sector. The analytical category "social participation" guided the data analysis. Results: Social participation was understood as "a mechanism of dialogue and conflict", "exercise of social control", "tool for achievement of the right and realization of society's desires" and "strategy to ensure the return of political propositions to the community". Conclusion: The actors perceive social participation as a means of ensuring the construction of the Food and Nutrition Security Policy and the achievement of the right to food by the population, although they also point out limitations on its effective exercise, a fact that will have an impact on other policies, such as the health policy.

Descriptors: Food and Nutrition Security; Social Participation; Public Policy. 


\section{RESUMEN}

Objetivo: Analizar la participación social a partir de la percepción de los actores sociales los cuales discuten e indican caminos para la Política de Seguridad Alimentaria y Nutricional (SAN). Métodos: Investigación realizada a través del método de estudio de caso en el período entre enero y noviembre de 2015 en nueve municipios de Maranhão con la aplicación de entrevistas semiestructuradas a 38 consejeros y miembros de las cámaras intersectoriales de seguridad alimentaria y nutricional siendo 22 de la sociedad civil y 16 del poder público. La categoría analítica "participación social" ha orientado el análisis de los datos. Resultados: La participación social ha sido vista como el "mecanismo de dialogo y conflicto", el "ejercicio del control social", el "instrumento para el alcance del derecho y realización de los anhelos de la sociedad" y la "estrategia para garantizar el regreso de las proposiciones de la política para la comunidad". Conclusión: Las percepciones de los actores se dirigen para la participación social como medio de garantizar la construcción de la política de SAN y el alcance del derecho de la población a alimentación. Sin embargo también señalan las limitaciones para su ejercicio efectivo que es un hecho que traerá impacto en otras políticas como la de la salud.

Descriptores: Seguridad Alimentaria y Nutricional; Participación Social; Política Pública.

\section{INTRODUÇÃO}

O combate à fome e à pobreza não é algo recente e segue sendo um tema regular nas discussões internacionais tendo em vista sua estreita vinculação com o progresso e o desenvolvimento das nações. Dessa maneira, não surpreende o fato dessas duas questões serem levantadas nos Objetivos de Desenvolvimento do Milênio, que surgiram na Declaração do Milênio das Nações Unidas, com o intuito de encorajar os governos a darem suporte a programas, serviços e organizações que buscam diminuir a insegurança alimentar entre as populações vulneráveis ${ }^{(1)}$.

No Brasil, o conceito de segurança alimentar toma força nos anos 1980, a partir da redemocratização do país, com grande participação da sociedade civil, que se mobiliza em torno da questão da fome e inicia a sua associação à cidadania ${ }^{(2)}$. Espaços como a VIII Conferência Nacional de Saúde, ocorrida em 1986, marco da participação popular no movimento da Reforma Sanitária, na qual foi realizada a I Conferência Nacional de Alimentação e Nutrição, dão início a esse processo de amplo debate em torno da questão alimentar e nutricional brasileira e à primeira proposição de um Sistema Nacional de Segurança Alimentar e Nutricional ${ }^{(3,4)}$.

Nesse mesmo período, como consequência da Reforma Sanitária, o movimento pela promoção da saúde tomava força no Brasil, dessa forma a Lei $n^{\circ}$ 8080/90 explicita em suas notas preliminares que a promoção, proteção e recuperação da saúde são partes integrantes da saúde da população, que é concebida como resultado de um conjunto de fatores, mencionados como determinantes e condicionantes, nos quais a alimentação está incluída ${ }^{(5)}$.

Dessa forma, a promoção da saúde expressa a necessidade de garantir, entre outras necessidades básicas, a alimentação. Profissionais de saúde ainda identificam, no entanto, a sua falta ou inadequação como uma questão recorrente na atividade como promotores de saúde ${ }^{(6)}$.

A compreensão de alimentação adequada está amplamente contemplada no conceito de Segurança Alimentar e Nutricional (SAN), que se consolidou a partir de mobilizações tais como a Ação da Cidadania (1992), que culminou na criação do Conselho Nacional de Segurança Alimentar e Nutricional (CONSEA), em 1993, composto por 1/3 de representantes do poder público e $2 / 3$ da sociedade civil, representando um espaço inédito para politizar a discussão da fome e ampliar a participação cidadã na formulação e controle das políticas públicas ${ }^{(2,7)}$.

Em 2004, realizou-se a II Conferência Nacional de Segurança Alimentar e Nutricional, na qual se adotou o significado da SAN como a "realização do direito de todos ao acesso regular e permanente a alimentos de qualidade, em quantidade suficiente, sem comprometer o acesso a outras necessidades essenciais, tendo como base práticas alimentares promotoras de saúde, que respeitem a diversidade cultural e que sejam ambiental, econômica e socialmente sustentáveis"(8).

Também é válido ressaltar outras conquistas no campo da SAN: a unificação dos principais programas de transferência de renda; a promulgação, em 2006, da Lei Orgânica de Segurança Alimentar e Nutricional (LOSAN), que estabelece a base legal para a criação do Sistema Nacional de Segurança Alimentar e Nutricional (SISAN) e a Emenda Constitucional 64/2010, que incluiu a alimentação entre os direitos sociais; a criação da Câmara Interministerial de Segurança Alimentar e Nutricional (CAISAN) e suas correspondentes nos estados e municípios; a publicação da Política Nacional de Segurança Alimentar e Nutricional, em 2010; e os esforços da União para implementar medidas de apoio aos governos estaduais, visando a implantação do $\operatorname{SISAN}^{(9)}$.

A participação da sociedade civil foi determinante para a inclusão da questão alimentar na agenda pública e a instauração dos marcos legais que a demarcam como um direito a ser assegurado pelo Estado, o que deu grande visibilidade ao Brasil no nível internacional ${ }^{(10)}$, sendo possivelmente o mais claro exemplo de uma construção em parceria Estado e sociedade entre 
as políticas públicas brasileiras, representada por técnicos e gerentes de diferentes setores governamentais e organizações sociais $^{(11)}$.

Dentre os marcos legais, há destaque para a LOSAN, que estabelece que o SISAN é regido pela participação social na "formulação, execução, acompanhamento, monitoramento e controle das políticas e dos planos de segurança alimentar e nutricional em todas as esferas de governo"(9). Contudo, essa participação pode variar conforme interesses e força de pressão dos diversos atores sociais representantes dos segmentos público e privado envolvidos no processo de construção da política pública. Além disso, outras questões relacionadas ao cenário sociopolítico também podem influenciar a implementação de políticas públicas, como a dinâmica institucional e as coalizões políticas que determinam as prioridades da agenda pública ${ }^{(12,13)}$.

Este artigo se propõe a analisar a participação social a partir da percepção dos atores sociais que discutem e indicam caminhos para a Política de Segurança Alimentar e Nutricional.

\section{MÉTODOS}

Trata-se de uma pesquisa qualitativa do tipo estudo de caso, um desenho metodológico que abrange desde o planejamento à análise dos resultados ${ }^{(14)}$. O estudo foi realizado entre janeiro e novembro de 2015, em nove municípios do estado do Maranhão, Brasil, que aderiram ao Sistema de Segurança Alimentar e Nutricional (SISAN) até o ano de 2014; portanto todos os municípios com instituição de conselho, câmara intersetorial e conferência municipal de SAN.

Participaram do estudo trinta e oito integrantes do Conselho de Segurança Alimentar e Nutricional (CONSEA) e/ou da Câmara Intersetorial de Segurança Alimentar e Nutricional (CAISAN), dos quais 22 (vinte e dois) eram representantes da sociedade civil e 16 (dezesseis) do poder público. Desses últimos, cinco participavam do CONSEA e da CAISAN; oito somente da CAISAN; e três integrantes participavam do CONSEA.

Para a escolha dos informantes, aplicou-se como critério de inclusão a assiduidade e protagonismo nas discussões e encaminhamentos nos respectivos espaços de participação. Para aplicação desse critério, o estudo contou com o auxílio de informantes-chaves: os presidentes dos conselhos no estado e município, e os gestores públicos que presidiam as CAISANs, pelo conhecimento sobre os participantes das referidas instâncias ${ }^{(15)}$. Adotou-se como critério de exclusão o afastamento das atividades nos conselhos e câmaras no período da pesquisa e a impossibilidade de comparecimento na localidade de aplicação das entrevistas.

Um dos principais embates epistemológicos entre as abordagens qualitativa e quantitativa é o posicionamento teórico que compreende a vida humana como uma atividade interativa e interpretativa; portanto o pesquisador qualitativo busca a compreensão, o significado do objeto estudado, de forma que os sujeitos do estudo são escolhidos de forma intencional, pois o que importa para essa abordagem não é o número de sujeitos, mas quão profundamente eles vivenciam o fenômeno em estudo e sua compreensão sobre o mesmo ${ }^{(15)}$. Assim sendo, os informantes que atendiam aos critérios estabelecidos e garantiam a inclusão dos diferentes sujeitos dos dois espaços de participação estudados integraram a presente pesquisa ${ }^{(16)}$.

Para a coleta dos dados, utilizou-se a entrevista semiestruturada, na qual as perguntas estruturadas abordavam a identificação dos sujeitos e as questões abertas investigavam sobre: "o que você entende por participação social?", "quanto tempo você está no CONSEA e que entidade você representa?", "o que significa representar tal segmento?", "fale da sua trajetória até ser conselheiro (a) no CONSEA", "você participa de algum outro conselho?", "você já participou de alguma Conferência de SAN e/ou Conferência de Políticas Públicas?", "quais ações do CONSEA você participou ativamente?”. Para o registro dos dados da entrevista, utilizou-se o recurso da gravação ${ }^{(16)}$ e não houve delimitação de tempo para o informante responder aos questionamentos.

Uma pesquisadora realizou as entrevistas em cada município, nos espaços físicos destinados aos Conselhos e/ou Secretarias que compunham as Câmaras Intersetoriais de Segurança Alimentar. Contudo, em alguns casos, os informantes tinham agenda de compromissos na capital do estado, sendo então entrevistados nessa ocasião.

Para proceder à análise dos dados das entrevistas, pesquisadores treinados para a atividade realizaram a transcrição. Posteriormente, deu-se início à análise temática ${ }^{(16)}$, com anotações de palavras-chaves e ideias que estivessem correlacionadas, com o foco na categoria analítica participação social.

A compreensão da categoria se refere à possibilidade de qualquer cidadão participar da tomada de decisões sobre políticas públicas, configurando-se essa participação como elemento central do exercício democrático ${ }^{(17,18)}$.

Para a caracterização dos informantes, utilizaram-se dados de identificação (idade, sexo, grau de instrução e formação/ ocupação) coletados durante a entrevista, que foram tabulados e quantificados.

As categorias empíricas que emergiram por meio da análise temática foram: "mecanismo de diálogo e conflito", "exercício de controle social", "instrumento para alcance do direito e realização dos anseios da sociedade" e "estratégia para garantir o retorno das proposições da política à comunidade".

O estudo obteve aprovação do Comitê de Ética em Pesquisa da Universidade Estadual do Ceará (sob o Parecer $n^{\circ}$ 1.001.981/2015) e houve formalização da adesão dos informantes por meio de assinatura do Termo de Consentimento Livre e Esclarecido (TCLE) $)^{(19)}$. 


\section{RESULTADOS E DISCUSSÃO}

Dados de caracterização dos informantes mostram que a maioria $(n=24 ; 63,2 \%)$ tinha idade entre 24 a 46 anos, com predomínio do sexo masculino e ensino superior completo ( $\mathrm{n}=25 ; 65,8 \%)$.

Para melhor descrição das categorias empíricas, houve o agrupamento em dois blocos temáticos: Participação social como interação entre poder público/ sociedade civil e retorno à comunidade; e Participação social como princípio da garantia do direito.

\section{Participação social como interação entre poder público-sociedade civil e retorno à comunidade}

Os conselheiros da sociedade civil compreendem a sua participação como forma de garantir o retorno dos benefícios propiciados pela política de SAN à comunidade:

"É sempre boa a participação social, no caso das entidades nas conferências, pois lá a gente vai estar definindo algumas coisas que vêm para o municipio no futuro. Isso que entendo por participação social" (CONSEA - sociedade civil).

"Eu entendo por participação social um modo como, assim, os projetos, as ações... levar até as pessoas que estão lá na base" (CONSEA - sociedade civil).

Compete às bases apoiar seus representantes nas questões relativas ao bem comum, uma vez que a eles delegaram autoridade para tal, configurando o direito e o dever do exercício do controle democrático ${ }^{(20)}$. A capacidade de representar bem a sua base é essencial, pois surgirão necessidades de deliberar sobre ações não conjecturadas nem pelo representante nem pelos representados ${ }^{(20)}$, dado ser o CONSEA municipal espaço privilegiado de discussão e deliberação sobre a política de SAN em nível local ${ }^{(21)}$.

Nesse aspecto, os CONSEAs se configuram como espaços de defesa dos interesses da sociedade civil organizada, bem como de grupos excluídos do acesso à alimentação adequada, que somente por esse caminho podem estar representados nos processos de formulação e gestão da política de SAN.

Dessa forma, além do retorno às suas bases, os informantes também percebem a participação como forma de colaborar na construção das políticas públicas e no controle social ao abordarem a necessidade de fiscalizar, monitorar as políticas, como modo de alcançar o direito humano à alimentação adequada e atender aos anseios da população:

"Eu entendo que a participação social é importante para que o sujeito possa, digamos assim, avaliar, monitorar as políticas. É importante a participação social na construção dessas políticas, porque não basta você só ser usuário da política, se você não participa. Nem sempre a política está de acordo com os anseios da população, e quando a gente participa tem a oportunidade de opinar, de avaliar, de dizer como é que a gente pensa aquela política e como ela se encaixa naquele determinado grupo social" (CONSEA - sociedade civil).

"É quando a pessoa tem a questão do acesso mesmo, está participando, a questão do controle também, que os conselhos têm esse papel. Do controle, do monitoramento, da participação" (CAISAN - poder público).

A participação social, ao ser referenciada como controle social, além de remeter à relação de fiscalização e monitoramento entre sociedade civil e Estado, retoma a necessidade de representação dos interesses da coletividade, com difusão de informação a todos, de modo que os interesses de uns não se sobreponham a outros ${ }^{(22)}$.

É importante verificar a compreensão dos conselhos como espaços onde poder público e sociedade civil se alternam e interagem na proposição de ações visando o bem comum, como sobressai no depoimento a seguir:

"Participação social, eu costumo de dizer que assim, nem todo mundo dirige carro, nem todo mundo dirige moto, nem todo mundo é motorista, mas todo mundo é pedestre. Eu costumo dar esse exemplo nos municipios. Eu digo que nem todo mundo é motorista, mas todo mundo é pedestre pra dizer que nem todo mundo é poder público, mas todo mundo é sociedade civil, porque aqueles que estão no poder público, eles quando saem da secretaria, ou quando estão na secretaria, o filho está na escola, o filho precisa de saúde, ele precisa de estrada asfaltada, ele precisa de saneamento básico. Então, nós somos eternamente sociedade civil. Então, o que é que eu entendo por participação social? É permitir que a sociedade na sua totalidade contribua com opiniões e com sugestões [...] é cobrar, é vigiar, é debater, é discutir e propor" (CONSEA - sociedade civil).

Tal compreensão explicita a ideia de que a relação Estado brasileiro/sociedade civil não é dicotômica, mas considera que a sociedade civil envolve relações sociais constituídas por todas as classes sociais em luta pela hegemonia, não sendo uma classe homogeneizada, e que, juntamente com a sociedade política, configura as ações do Estado ${ }^{(23)}$.

Essa compreensão é fundamental dada a complexidade de indivíduos e instituições que compõem a sociedade civil, e de grande importância para a definição de políticas públicas de promoção da saúde, na qual a participação social é condição para a eleição de prioridades a partir das necessidades reais da população, de forma a incluir parcelas da sociedade historicamente excluídas $^{(5,24)}$. 


\section{Participação social como princípio da garantia do direito}

A LOSAN explicita a alimentação adequada como "um direito fundamental do ser humano, inerente à dignidade da pessoa humana e indispensável à realização dos direitos consagrados na Constituição Federal, devendo o poder público adotar as políticas e ações que se façam necessárias para promover e garantir a segurança alimentar e nutricional da população"(25). O SISAN é o dispositivo legal que assegura esse direito e, para a adesão ao referido sistema, estados e municípios precisam criar uma estrutura mínima composta pelos conselhos, câmaras intersetoriais, conferências e os planos de $\mathrm{SAN}^{(8,25)}$.

O panorama histórico e social em que se iniciam as conquistas da política de SAN tem a marca da contradição, pois enquanto se dá a reconstrução e ampliação da democracia, com a criação de espaços institucionais de participação social contemplados na Constituição Cidadã, instala-se no Brasil a política neoliberal, na qual se negam direitos ${ }^{(26)}$.

As políticas de saúde e de segurança alimentar e nutricional, para citar duas necessidades básicas à vida humana, incluem o princípio da participação social, que é inerente à promoção da saúde. Ao prevalecer políticas de cunho neoliberal, a participação social perde parte de seu potencial como indutora de políticas que promovam saúde e qualidade de $\operatorname{vida}^{(27,28)}$.

Dessa forma, os desafios para a participação social e seu papel na garantia dos direitos conquistados são vários e complexos, passam pelas políticas de cunho neoliberal e a incipiente cultura democrática até o tradicional autoritarismo do Estado brasileiro $^{(29,30)}$.

É provável que um dos achados do presente estudo seja decorrente da pouca cultura democrática, que concorre para a resistência de participação nos espaços de discussão e deliberação políticas, o que se reflete na demanda de participação de um mesmo indivíduo em vários conselhos sociais.

A maioria dos informantes $(\mathrm{n}=22 ; 57,8 \%)$ participava de dois ou mais conselhos, o que pode representar um entrave à participação plena diante da dificuldade de acompanhamento de todas as atividades propostas e aprofundamento na política a ser discutida, podendo contribuir para a redução das políticas públicas à legitimação dos interesses do capital e distanciamento da questão social.

"[...] dentro do que a gente trabalha, a gente tem que se doar ao máximo para que não fique só aquela coisa de representar, tem que estar presente, e estar presente é o compromisso de estar participando ativamente. Então eu achava que era muito, são muitos conselhos e eu gostaria de participar de muitos ativamente, então, como eu não podia participar ativamente, eu deixei a quem de direito pudesse se doar" (CONSEA - poder público).

Numa outra perspectiva, os espaços de participação social se configuram como espaços de conflito, onde os participantes podem contribuir para fortalecer ou fragilizar o exercício da participação ${ }^{(30)}$. Os conselhos carregam contradições, já que "[...] podem alavancar o processo de participação de grupos organizados como podem estagnar o sentimento de pertencimento de outros se monopolizados por indivíduos que não representem de fato as comunidades que os indicaram/elegeram"(30).

Também na percepção dos informantes a participação tem essa característica de ser instrumento de diálogo e conflito:

"[...] é o movimento em que a sociedade está sempre buscando, brigando" (CONSEA - sociedade civil).

[...] a participação social está incluída na nossa Constituição Brasileira, juridicamente como a democracia participativa e significa dizer que é um instrumento de diálogo e de conflito, você tem que dialogar, mas tem que ser conflitivo [...]" (CONSEA - sociedade civil).

O fortalecimento da participação social ou sua fragilidade, isto é, seu sucesso ou fracasso, dependem do grau de organização da sociedade civil ${ }^{(29)}$. Nesse sentido, os conselhos de SAN se destacam como espaços que possibilitam aos grupos excluídos do acesso à alimentação adequada participarem do processo de formulação e gestão da política de SAN, pois, pela sua composição, $1 / 3$ de representantes deve ser do poder público e $2 / 3$ da sociedade civil organizada, devendo contemplar a participação de representações de segmentos populacionais socialmente vulneráveis, portanto dos grupos historicamente afetados pela insegurança alimentar, o que supostamente confere legitimidade aos CONSEAs.

É necessário, contudo, o questionamento sobre a qualificação dos representantes ou de seu compromisso com os representados. A qualificação para a participação cidadã vincula-se ao conceito de democracia e, portanto, ao próprio exercício democrático, porque pressupõe que os cidadãos participem da elaboração das tomadas de decisões. Os conselhos devem ser espaços de participação sem nenhuma forma de discriminação, e os conselheiros, cidadãos autorizados a participar da democracia $^{(17)}$. Nesse aspecto, o presente estudo traz um resultado preocupante sobre a forma como, em alguns casos, são escolhidos os representantes nos CONSEAs:

"Os conselheiros que são escolhidos, vamos dizer, aqui [...] eles são mais apadrinhados entre prefeitos. Conselho, como a gente já teve várias capacitações, é para fazer defesa, é pra o controle social, não é pra apadrinhar as autoridades, [...] mas os conselheiros quando eles não são funcionários do município, fornecem alguma coisa pro município. E eu sempre nas minhas reuniões eu disse, se você não tem condições de ser conselheiro, entregue, eu tenho certeza que vai aparecer outro que tenha coragem" (CONSEA - sociedade civil). 
Tal procedimento reduz o potencial do conselho por confrontar algumas características essenciais da participação social enquanto exercício democrático, tais como: liberdade de participação, participação ativa e refletida, distribuição de poder entre os membros da comunidade, representação dos mais desiguais ${ }^{(17)}$; portanto "quem participa" é determinante do tipo de participação.

São três os tipos de participação: a pseudoparticipação, no sentido de persuasão para que decisões já tomadas sejam aceitas, não refletindo em uma participação real; participação parcial, em que não há igual poder de decisão entre os indivíduos, podendo a participação apenas influenciar uma decisão já existente, mas não determiná-la; participação plena, na qual todos os membros participam da mesma forma, por terem informações suficientes e igual poder de decisão ${ }^{(31)}$.

No cenário do presente estudo, o exercício da participação parcial nos conselhos de SAN sobressai ao se verificar que os conselheiros da sociedade civil, que deveriam representar e defender os interesses das entidades e pessoas que representam, defendem os seus interesses pessoais ou legitimam decisões de interesse do poder público, contribuindo para a manutenção do status quo e minando o potencial do CONSEA como espaço de defesa dos interesses da sociedade civil e de inclusão dos grupos da população mais vulneráveis à insegurança alimentar e nutricional.

No que concerne às instâncias representativas, como o Conselho de Saúde, além da defesa de interesses pessoais, os representantes também podem defender interesses institucionais em defesa de seus segmentos e interesses amplos sobre a política, logo, essa representatividade só poderá ser garantida mediante a interação com as bases representadas e o envolvimento e participação da comunidade ${ }^{(32)}$.

Entre alguns informantes do atual estudo, também há a compreensão do exercício da participação social como interação com as bases e defesa de direitos dos representados:

“A participação social é quando realmente nós somos incluídos dentro das políticas públicas, somos respeitados, somos recebidos de forma que venha justamente satisfazer, não o ego, mas a questão social mesmo" (CONSEA - sociedade civil).

"[...] espaço onde nós podemos exercer a nossa cidadania não só vendo o nosso lado pessoal, trazendo uma reflexão para além do "eu”, mas com foco nas outras pessoas, de que forma nós, enquanto sociedade civil, podemos contribuir na luta dos seus direitos" (CONSEA - poder público).

Este bloco temático evidencia ser a participação social na política de SAN um objeto em construção, que requer especial atenção, uma vez que, para se configurar como sistema nos estados e municípios, o SISAN requer uma estrutura mínima na qual está contemplado o CONSEA. A criação desses espaços por uma exigência institucional, entretanto, envolve o risco de sua desqualificação como espaço de participação social e arena decisória da política de SAN, reduzindo sua potencial contribuição para assegurar o direito à alimentação.

Ao considerar a alimentação como um dos condicionantes da Saúde, compreende-se que sua negação enquanto direito gera impactos, inclusive orçamentários, à Política de Saúde, "a exemplo da obesidade, desnutrição e carências nutricionais específicas, que recaem sobre o setor saúde"(33). Diante da notória importância temática, a Política Nacional de Promoção da Saúde (PNPS) já prevê ações direcionadas ao alcance da Segurança Alimentar e Nutricional, assim como a temática ganha destaque entre as publicações da área $\mathrm{PNPS}^{(34)}$.

As diferentes categorias empíricas apresentadas se direcionam para a participação social como um meio de garantir a construção da política de SAN e o alcance do direito à alimentação pela população. Destacam-se ainda nesse estudo os aspectos importantes da participação social na política de SAN, que apontam avanços e desafios para a qualificação da participação como exercício democrático capaz de contribuir na consolidação do SISAN e na garantia do direito à alimentação.

A partir das falas, perceberam-se avanços (como a compreensão da participação social enquanto potencial para promover equidade, por possibilitar aos representantes a luta pela garantia de retorno dos benefícios propiciados pela política aos representados e oportunidade de colaborar na construção das políticas públicas); a percepção dos conselhos como espaços onde poder público e sociedade civil se alternam e interagem na proposição de ações visando o bem comum; a participação social como potência do conflito e do diálogo; e os CONSEAs e as conferências como espaços legítimos de participação.

Configuram-se como desafios: a pouca difusão de informações e insuficiente comunicação entre instituições e atores sociais envolvidos na política de SAN; a necessidade de qualificação da participação; e os CONSEAs como espaço de participação parcial.

O presente estudo apresenta limitações, tais como: o fato de não haver estudado outros aspectos relacionados à prática da participação social dos sujeitos nem a dificuldade de acesso a outras pesquisas que investigassem a participação social na área de SAN, as quais poderiam enriquecer as discussões.

\section{CONSIDERAÇÕES FINAIS}

As percepções dos atores investigados no presente estudo se direcionam para a participação social como um meio de garantir a construção da Política de Segurança Alimentar e Nutricional (SAN) e o alcance do direito à alimentação pela população. 
Porém também sinalizam limitações para o seu efetivo exercício, fato que terá impacto em outras políticas, como a da saúde. Desse modo, aponta-se para a necessidade de fortalecimento da atuação dos sujeitos historicamente alijados do processo de construção e execução das políticas públicas.

\section{REFERÊNCIAS}

1. García ALR, Palacio LMA, Erazo-Coronado AM, Pérez MA. Food Security Overview: the Colombia experience. Salud Uninorte. 2015;31(1):181-9.

2. Rocha EG. A construção democrática do direito à alimentação adequada e a regulação de alimentos. Rev Direito Sanit. 2017;17(3):107-12.

3. Silva SP. A trajetória histórica da segurança alimentar e nutricional na agenda política nacional: projetos, descontinuidades e consolidação. Rio de Janeiro: IPEA; 2014.

4. Burlandy L, Magalhães R, Frozi D. Políticas públicas de Segurança Alimentar e Nutricional. In: Rocha C, Burlandy L, Magalhaes R, organizadores. Segurança alimentar e nutricional: perspectivas, aprendizados e desafios para as políticas públicas. Rio de Janeiro: FIOCRUZ; 2013. p. 89-110.

5. Ávila MMM, Pitombeira DF, Catrib AMF. Promoção da saúde: pensando a saúde de forma afirmativa. In: Moreira TMM, Ávila MMM, Jorge MSB, Leitão IMTA. Manual de Saúde Coletiva. Salvador: Sanar; 2016. p.125-40.

6. Zanchetta MS, Kolawola-Salami B, Bailey A, Guruge S, Ohama A, Renauld L, et al. Enhancing critical reflection of brazilian community health agents' awareness of social determinants of heath. SAGE Open. 2014:1-14.

7. Leão $\mathrm{M}$, organizador. O direito humano à alimentação adequada e o Sistema Nacional de Segurança Alimentar e Nutricional. Brasília: Abrandh; 2013.

8. Conselho Nacional de Segurança Alimentar e Nutricional (BR). Princípios e diretrizes de uma política de segurança alimentar e nutricional. Brasília: CONSEA; 2004.

9. Ávila MMM, Costa MCO. A participação social e o direito humano à alimentação adequada no contexto brasileiro. Nutrivisa. 2015;2(2):51-3.

10. Burlandy L, Rocha C, Maluf RS, Ávila MMM, Ferreira DM, Pereira SEA. Cooperação internacional em SAN: sistematização de práticas educativas participativas, contextualizadas e intersetoriais. Rev Nutr. 2016;29(6):929-46.

11. Burlandy L. A atuação da sociedade civil na construção do campo de Alimentação e Nutrição no Brasil: elementos para reflexão. Ciênc Saúde Coletiva. 2011;16(1):63-72.

12. Côrtes SV. Viabilizando a participação em conselhos de política pública municipais: arcabouço institucional, organização do movimento popular e policy comunities. In: Hockman G, Arretche M, Marques E, organizadores. Políticas públicas no Brasil. Rio de Janeiro: FIOCRUZ; 2007. p. 125-43.

13. Rocha NC, Doria NG, Boia JM; Bógus CM. Organização e dinâmica do Conselho Municipal de Segurança Alimentar e Nutricional de São Paulo: implicações para a sua atuação na construção da política municipal de Segurança Alimentar e Nutricional. Rev Nutr. 2012; 25(1):133-46.

14. Yin RK. Estudo de caso: planejamento e métodos. $5^{\text {a }}$ ed. Porto Alegre: Bookman; 2014.

15. Guerra ELA. Manual de pesquisa qualitativa. Belo Horizonte: Grupo Anima Educação; 2014.

16. Minayo MCS. O desafio do conhecimento: pesquisa qualitativa em saúde. $10^{\mathrm{a}}$ ed. São Paulo: Hucitec; 2010.

17. Ugarte PS. Que participação para qual democracia? In: Coelho VSP, Nobre M, organizadores. Participação e deliberação: teoria democrática e as experiências institucionais no Brasil contemporâneo. 34 ed. São Paulo; 2004. p.93-106.

18. Demo P. Participação é conquista: noções de política social participativa. $6^{a}$ ed. São Paulo: Corte; 2009.

19. Conselho Nacional de Saúde (BR). Resolução n 466, de 12 de dezembro de 2012. Dispõe sobre as diretrizes e normas regulamentadoras de pesquisas envolvendo seres humanos. Diário Oficial União; 13 jun. 2013. Seção 1.

20. Lattman-Weltman F. Democracia, representação, participação: a aposta do pluralismo institucional. Divulg Saúde Debate. 2008;(43):29-36.

21. Diegues GC. O controle social e participação nas políticas públicas: o caso dos conselhos gestores municipais. Rev NAU Social. 2013;4(6):82-93 
22. Soratto J, Rigatto WR. Participação e controle social: percepção dos trabalhadores da saúde da família. Texto \& Contexto Enferm. 2013; 22( 1 ):89-96.

23. Pinheiro L. Apresentação - democracia e saúde: sociedade civil, cidadania e cultura política. Physis (Rio de J). 2004; 14(1):11-14.

24. Labonte R. Social inclusion/exclusion and health: dancing the dialetic. In: Raphael D. Social determinantes of health. $2^{\text {nd }}$ ed. Toronto: Canadian Scholar's Press Inc.; 2009. p. 269-79.

25. Brasil. Lei n. 11.346, de 15 set 2006. Lei Orgânica de Segurança Alimentar e Nutricional (LOSAN). Cria o Sistema Nacional de Segurança Alimentar e Nutricional - SISAN com vistas em assegurar o direito humano à alimentação adequada e dá outras providências [acesso em 2016 Jul 15]. Disponível em: http://www.planalto.gov.br/ccivil_03/_ato2004-2006/2006/ lei/111346.htm

26. Albuquerque MC, organizador. Participação popular em políticas públicas: espaço de construção da democracia brasileira. São Paulo: Instituto Pólis; 2006.

27. Bravo MIS, Correia MVC. Desafios do controle social na atualidade. Serv Soc Soci. 2012;(109):126-50.

28. Carvalho JM. Cidadania no Brasil: o longo caminho. 15ª ed. Rio de Janeiro: Civilização Brasileira; 2012.

29. Coelho VSP. Conselhos de saúde enquanto instituições políticas: o que está faltando? In: Coelho VSP, Nobre M, organizadores. Participação e deliberação: teoria democrática e as experiências institucionais no Brasil contemporâneo. São Paulo: Ed 34; 2004. p. 255-69.

30. Gohn MG. Sociedade Civil no Brasil: movimentos sociais e ONGs. Meta Avaliação 2013;5(14):238-53.

31. Pateman C. Participação e teoria democrática. Rio de Janeiro: Paz e Terra; 1992.

32. Bispo JP Júnior, Gerschman S. Legitimidade da representação em instâncias de participação social: o caso do Conselho Estadual de Saúde da Bahia, Brasil. Cad Saúde Pública. 2015; 1(1):183-93.

33. Alves KPS, Jaime PC. A política nacional de alimentação e nutrição e seu diálogo com a Política Nacional de Segurança alimentar e Nutricional. Ciênc Saúde Coletiva. 2014;19(11):4331-40.

34. Yamaguchi MU, Bernuci MP, Pavanelli GC. Produção científica sobre a Política Nacional de Promoção da Saúde. Ciênc Saúde Coletiva. 2016;21(6):1727-36.

\section{Endereço do primeiro autor:}

Alessandra Karla Oliveira Amorim Muniz

Universidade Estadual do Ceará - UECE

Coordenação do Curso de Mestrado Acadêmico em Nutrição e Saúde (CMANS)

Av. Dr. Silas Munguba, 1700

Bairro: Itaperi

CEP: 60740-903 - Fortaleza - CE - Brasil

E-mail: alessandrakoa@hotmail.com

\section{Endereço para correspondência:}

Letícia de Albuquerque Araújo

Universidade Estadual do Ceará - UECE

Av. Dr. Silas Munguba, 1700

Bairro: Itaperi

CEP: 60.714.903 - Fortaleza - CE - Brasil

E-mail: leticiadeaa@gmail.com 